\title{
Revolusi sumber-sumber informasi di internet Dan hubungannya dengan masyarakat informasi
}

\author{
Testiani Makmur \\ Mahasiswa Pascasarjana-S3, Kosentrasi Ilmu Perpustakaan dan Informasi \\ UIN Sunan Kalijaga, Yogyakarta \\ Testianisr28@gmail.com
}

\begin{abstract}
This paper aims to review the main expertise that the information community must have over the revolution in information resources on the internet. Literary-based methodology related to literacy, information sources and information tracking strategies. The implication is to help the information society know as well as their expectations in daily life in (1) equipping themselves with information literacy and the success of information literacy can be viewed from the ability of the information community to apply information resources correctly and according to needs, (2) to know the sources of information in internet such as e-book, e-journal etc., and (3) understand information tracking strategies and the need for information search strategies so that they are not trapped with millions of information, are strayed on the Search Engine pages, don't spend long periods of time choosing, filtering or judging information overload, eventually not obtain appropriate information and have an impact on the level of satisfaction.
\end{abstract}

Keywords: Revolution, Information Sources, Internet, Information Society

\begin{abstract}
ABSTRAK
Makalah ini bertujuan untuk mengulas tentang keahlian utama yang harus dimiliki masyarakat informasi atas revolusi sumber informasi di internet. Metodologi berbasis literature yang berkaitan dengan literasi, sumber-sumber informasi dan starategi penulusaran informasi. Implikasinya membantu masyarakat informasi mengetahui sekaligus penarapannya dalam kehidupan sehari dalam (1) membekali diri dengan literasi informasi dan keberhasilan literasi informasi dapat ditinjau dari kemampuan masyarakat informasi dalam mengaplikasikan sumber-sumber informasi secara benar dan sesuai kebutuhan, (2) mengenal sumber-sumber informasi di internet seperti ebook, ejournal dsb, dan (3) paham strategi penelusuri informasi dan perlunya strategi penelusuran informasi agar tidak terjebak dengan jutaan informasi, tersasar di halaman Search Engine, tidak menghabiskan waktu lama, kebinggungan memilih, menyaring atau menilai informasi yang overload, akhirnya tidak memperoleh informasi yang sesuai dan berdampak pada tingkat kepuasan.
\end{abstract}

Kata Kunci: Revolusi, Sumber Informasi, Internet, Masyarakat Informasi

\section{A. PENDAHULUAN}

Sejarah revolusi informasi terjadi perbedaan, ada yang mengatakan awal mula revolusi informasi dikenalkan oleh William pada awal tahun 1947 yang menemukan sistim transistor di Labotarium Bell Telephone New Jersey dan dari penemuan tersebut mempercepat transformasi yang berlanjut dengan peningkatan sistem computer. Di versi yang lain diutarakan Wiener tahun 1948 mengutarakan revolusi informasi terjadi setelah perang dunia kedua yang merupakan pengaruh dari pertumbuhan teknologi. Namun penjelasan Webster $(1995,9)$ dari 1970 hingga 1980 terjadi metafora revolusi teknologi yaitu terdiri revolusi pertanian, revolusi industry dan revolusi informasi. Atas kehadiran dan revolusi teknologi 
menjadi salah satu faktor memberikan kontribusi terciptanya atau berkembangnya revolusi informasi dan sumber-sumber informasi.

Revolusi informasi sering disebut sebagai abad informasi dan semulanya informasi sebatas teks-teks akan tetapi informasi sudah bergeser dalam bentuk multimedia seperti informasi video, audio, dan video visual. Revolusi informasi umum dimaknai sebagai perubahan yang diproduksi teknologi informasi (Ahmad 2012, 139), berpengaruh pada proses reproduksi dan penyembaran informasi, berimbas pada pergesaran corak dan bentuk dari penyajian informasi (Masiani 2015, 36), setiap orang mampu melahirkan, mengakses, memanfaat dan berbagi informasi maupun pengetahun(Sukaesih and Rohman 2013, 62), merubah kebiasaan masyarakat dalam berbagi informasi dan mengakses informasi dari konsep konvesional menjadi digital, kesadaran akan informasi serta akhirnya melahirkan sumber-sumber informasi berbasis digital (elektronik). Misalnya untuk memperoleh informasi singkat dan padat cukup mencari di twitter, informasi yang menampilkan gambargambar diperoleh dari instgram, informasi mengandung unsur suara, gambar dan teks tinggal klik Youtube, informasi bersifat ilmiah bisa diakses di Academia, Repository, Researchgate, Google Scholar dan sebagainya. Situasi ini, tentu menguntungkan masyarakat informasi karena dimanjakan dengan ragam informasi, mempunyai berbagai alternative sumber infomrasi dalam memenuhi dan melengkapi kebutuhan informasi.

Kemudian akan berdampak pula pada (1) Informasi berlimpah ruah yang merupakan fenomena dari penciptaan informasi, (2) Kemudahan desiminasi informasi, (3) Kemudahan akses, (4) Kemudahan pertukaran informasi tanpa adanya filter, tanpa editor atau tanpa redaksi, (5) Mendorong siapapun untuk berbagi informasi, yang mulanya penyerabaran informasi berupa konvensional dan kini berubah menjadi penyebaran informasi digital, dan (6) Tersedianya perangkat teknologi canggih yang dilengkapi fitur-fitur untuk mengakses informasi digital dengan harga terjangkau serta mampu menyimpan informasi dengan kapasitas besar(Suadi and Makmur 2015, 1).

Namun berlimpah ruahnya informasi terdapat peluang dan tantangan yang akan dihadapi masyarakat informasi (Ardoni 2005, 1). Peluangnya ialah memberikan kemudahan kepada masyarakat informasi untuk mendapatkan berbagai jenis informasi melalui mediamedia yang tersedia, baik media tercetak maupun media elektronik, memiliki kebebasan untuk memilih jenis media yang digunakan dalam memenuhi kebutuhan informasi (Rifai n.d.), begitu mudah memperoleh informasi yang up to date, cepat, serta dapat diakses dari mana saja dan kapan saja (Triningsih n.d.). Sedangkan tantangan yang harus dihadapi masyarakat informasi diantaranya bagaimana menghadapi ataupun menguasai sumbersumber informasi, pertanyakan kesahihan atau kebenarannya informasi karena tidak seluruh informasi mampu diserapkan serta dievaluasi masyarakat informasi.

Ditambah pula informasi yang tersedia di internet lebih dari 50 persen mengandung informasi sampah (Surachman 2017, 8). Apalagi merujuk data tentang kemajuan teknologi yang berdampak pada informasi yaitu menghasilkan sekitar 2,5 exabytes data yang dibuat setiap hari, angka tersebut berkembang dua kali lipat setiap 40 bulan, begitupun yang dirilis oleh Infographiclist.com yaitu setiap hari terdapat 15 Terabytes (TB) informasi di produksi di internet, setiap hari ada milyaran data atau informasi yang diindeks google, tercatat lebih 120 juta blog, 200 juta website di internet, dan ditambah pula ragam informasi multimedia informasi yang disuguhi dari sosial media (youtube, facebook, twitter). Namun dengan keberlimpahan informasi sesungguhnya telah di perkirakan oleh Futurologist Alvin Toffer pada tahun 1980 dan kini telah menjadi kenyataan (Toffler 1980, 156). Hal tersebut sejalan pula dengan kebutuhan informasi pada masyarakat informasi.

Lalu apakah beraneka macam bentuk penyedian informasi dan sumber-sumber informasi memberi kemudahan, memberi banyak pilihan untuk memperoleh informasi atau 
sebaliknya? Inilah yang harus dijawabkan oleh masyarakat informasi (Suadi and Makmur 2015, 18). Hal sama juga diutarakan Webster $(1995,11)$ dimana setiap masyarakat informasi memiliki perangkat teknologi, namun apakah dengan kepemilikan teknologi informasi sudah didukung dengan kemampuan menggunakannya. Apalagi dengan overloadnya informasi menyebabkan masyarakat informasi kerap mendepati kerumitan untuk memperoleh informasi yang dibutuhkan(Hakim 2015) dan munculnya pertanyaan tentang kredibilitas informasi(Muntasir, n.d.). Kondisi seperti ini tentunya memberi konsekuensi sendiri bagi masyarakat informasi dan dibutuhkan keahlian yang mampu menghindari dampak tersebut.

Keahlian utama yang dibutuhkan masyarakat informasi atas revolusi sumber informasi, yaitu membekali diri dengan literasi informasi, mengenal sumber-sumber informasi, dan paham strategi penelusuran informasi. Karena dengan berlimpah ruah informasi dan teknologi tidak serta merta akan membuat masyarakat informasi paham halhal tersebut. Maka dari itu pentingnya mengulas elemen-elemen tersebut untuk menghindari terjadinya kesenjangan informasi pada masyarakat informasi dan mampu menulusuri informasi secara efektif. Sedangkan ciri-ciri masyarakat informasi yaitu kemampuan menyerap informasi (Ardoni 2005, 3), kebutuhan akan informasi sangat tinggi, bergantung pada inovasi teknologi (Webster 1995, 8), kaya informasi, berbasis pengetahuan, kemahiran menelusuri informasi, mengenal media penyimpan informasi agar terhindari dari kendala serta sebagai jembatan dalam mengidentifikasi informasi yang dibutuhkan benar-benar valid, akurat, ilmiah (Suadi and Makmur 2015, 22). Seperti diketahui secara bersama tidak semua informasi bertebaran atau tersedia di dunia internet dapat menjadi acuan, menjadi pedoman terutama dijadikan referensi akademis, ilmiah ataupun sumber membuat kebijakan (Suadi and Makmur 2015, 29).

\section{B. LITERASI INFORMASI}

Dengan munculnya bermacam-macam cara menelusur sumber-sumber informasi, seharusnya berbanding lurus dengan wawasan dan tingkat literasi informasi. Sebagaimana hasil penelitian O'Connor,L. dan Newby menyimpulkan literasi informasi merupakan dasar utama dalam penelusuran informasi agar mampu mengumpul, menyaring, memiliah berbagai informasi ( $\mathrm{O}^{\prime}$ Connor and Newby n.d.). Literasi informasi ialah berpengalaman dalam memanfaatkan sumber-sumber informasi (Badke n.d.), terlatih dan terus memperdalami metode menggunakan alat-alat maupun sumber utama informasi (Sudarsono 2007, 27), menyadari kebutuhan informasi dan mampu menemukan informasi yang dibutuhkan dalam menyelesaikan masalah (UNESCO n.d.), mengorganisasi dan mengintergarasikan dengan ilmu pengatahuan yang dimiliki lalu mengkomunikasi informasi(Darmono 2007, 19), dan kemampuan analitikal dan kritis atas informasi yang diperoleh (Nuryaman n.d.).

Manfaat literasi informasi bagi masyarakat informasi dalam menghadapi revolusi informasi yaitu menjadi pembelajaran sepanjang hayat, kritis dan mampu melebarkan kerangka berpikir tatkala berinteraksi dengan beragam-ragam informasi (Iskandar 2016, 5). Sementara keberhasilan literasi informasi dapat ditinjau dari kemampuan masyarakat informasi dalam mengaplikasikan sumber-sumber informasi secara benar dan sesuai kebutuhan(Iskandar 2016, 6).

Cara menumbuh dan meningkat literasi informasi pada masyarakat informasi yaitu perlunya kerjasama berbagai stakeholder untuk terus melakukan sosialisasi, supaya ada kesadaran tentang pentingnya literasi informasi dalam menghadapi revolusi informasi. Misalnya (1) Adanya kesadaran masyarakat informasi untuk memiliki keahlian literasi informasi dengan mengikuti pelatihan atau belajar secara mandiri melalui buku pedoman ataupun diinternet, (2) Dituntut tanggungjawab pustakawan sebagai manager informasi 
memberi pendidikan pemakai dalam menelusuri informasi dan mengenal sumber-sumber informasi, (3) Perpustakaan memberi pelatihan atau seminar-seminar gratis secara berkelanjutan bagi masyarakat informasi dalam pengenalan ataupun peningkat literasi informasi, (4) Bagi dunia pendidikan menyelaraskan kurikulum dengan menghadirkan mata kuliah literasi informasi, dan dari pihak pemerintah melakukan pelatihan-pelatihan bagaimana bijak atau kritis terhadap informasi karena itu salah satu bagian dari literasi informasi. Sebagaimana hasil penelitian Aniyah $(2017,65)$ bahwasanya dengan memasukan ide literasi pada pendidikan merupakan langkah sangat tepat dalam upaya mengikuti perkembangan zaman terutama keragaman informasi.

\section{SUMBER-SUMBER INFORMASI DI INTERNET}

Dampak dari revolusi informasi yaitu keberlimpahan informasi menjadi semakin beragam. Sehingga memberi kebebasan dan kemudahan masyarakat informasi dalam menulusuri sumber-sumber informasi di internet serta kebutuhan akan informasi semakin meningkat. Dalam memenuhi peningkatan kebutuhan masyarakat informasi harus mengenal-mengenal sumber informasi dan sumber informasi internet antara lain:

\section{1. (Online Public Access Catalog)}

Suatu sistem temu balik informasi berbasis komputer yang digunakan oleh pengguna untuk menelusur koleksi suatu perpustakaan atau unit informasi lainnya, bisa ditelusuri berdasarkan Query (keyword, judul buku, pengarang, ISBN, tempat terbit, bentuk fisik, penerbit), menunjukkan keberadaan atau kekayaan koleksi dari suatu perpustakaan tertentu sehingga pengguna bisa mengetahui informasi tentang jumlah judul, subjek, eksemplar, dan sebagainya. Misalnya katalog yang bisa digunakan masyarakat informasi dalam memenuhi kebutuhan yaitu http://bni.pnri.go.id dan sebagainya

\section{Repository}

Kehadiran sumber informasi berupa Repositoy memberi solusi bagi masayakat untuk mencari dan memenuhi informasi terutama yang bersifat ilmiah serta bisa dipertanggungjawabkan kebenarannya. Umumnya repository hampir dimiliki seluruh instansi, lembaga, dan perguruan tinggi. Repository merupakan karya ilmiah misalnya disertasi, tesis, skrispsi, tugas akhir, pidato, makalah seminar, kertas karya yang dihasilkan oleh mahasiswa, sedangkan yang dihasilkan dosen berupa artikel, laporan penelitian, dan karya lainnya tentang Universitas maupun diluar konten akademis. Repository setiap instansi atau Universitas akan memeliki koleksi berbeda-berbeda dan saling melenagkapi. Untuk mengetahui secara awal jenis koleksi repository yang dimiliki oleh setiap Universitas ataupun instansi yaitu dari misi, visi atau bidang-bidang yang tersedia masing-masing lembaga (Suadi and Makmur 2015, 58).

Repository (IR) merupakan suatu tempat atau ruang digital untuk mengelola berbagai jenis koleksi intelektual yang telah dialihkan bentuk digital yang dihasilkan dari lembaga, perorangan, group atau pihak luar belum pernah diterbitkan sebelumnya. Koleksi repository diperuntuk bagi pihak internal maupun eksternal. Bagi eksternal harus memenuhi syarat terlebih dahulu jika ingin membaca dan bisa menjadi sarana lifelong learning bagi siapapun terutama bagi kalangan akademik (Suadi and Makmur 2015, 62).

Tabel 1. Repositori Peringkat 10 Terbaik di Indonesia

\begin{tabular}{|c|l|l|}
\hline No & \multicolumn{1}{|c|}{ Nama Institusi } & \multicolumn{1}{c|}{ Alamat } \\
\hline 1 & Diponegoro University Institutional Repository & http://eprints.undip.ac.id/ \\
\hline 2 & Yogyakarta State University Repository & http://eprints.uny.ac.id/ \\
\hline 3 & $\begin{array}{l}\text { Digital Library Universitas Islam Negeri Sunan } \\
\text { Kalijaga Yogyakarta }\end{array}$ & http://digilib.uin-suka.ac.id/ \\
\hline
\end{tabular}




\begin{tabular}{|c|l|l|}
\hline 4 & $\begin{array}{l}\text { Universitas Sebelas Maret Institutional } \\
\text { Repository }\end{array}$ & http://eprints.uns.ac.id/ \\
\hline 5 & $\begin{array}{l}\text { Bogor Agricultural University Scientific } \\
\text { Repository }\end{array}$ & http://repository.ipb.ac.id/ \\
\hline 6 & Digital Repository Universitas Negeri Medan & http://digilib.unimed.ac.id/ \\
\hline 7 & Andalas University Repository & http://repository.unand.ac.id/ \\
\hline 8 & Hasanuddin University Repository & http://repository.unhas.ac.id/ \\
\hline 9 & $\begin{array}{l}\text { Institut Teknologi Sepuluh Nopemeber } \\
\text { Repository }\end{array}$ & http://repository.unhas.ac.id/ \\
\hline 10 & Digital Library of Institut Teknologi Bandung & http://digilib.itb.ac.id/ \\
\hline
\end{tabular}

Tabel 2. Repositori Peringkat 10 Terbaik di Dunia

\begin{tabular}{|c|l|l|}
\hline No & \multicolumn{1}{|c|}{ Nama Institusi Terbaik Dunia } & \multicolumn{1}{c|}{ Alamat } \\
\hline 1 & Cornel University Library & http://arxiv.org/ \\
\hline 2 & Social Science Research Network & http://ssrn.com/ \\
\hline 3 & Europe PubMed Central & http://europepmc.org/ \\
\hline 4 & Research Papers in Economics & http://repec.org/ \\
\hline 5 & $\begin{array}{l}\text { HAL Institut National de Recherche en } \\
\text { Informatique et en Automatique Archive Ouverte }\end{array}$ & http://hal.inria.fr/ \\
\hline 6 & Universtity California & http://escholarship.org/ \\
\hline 7 & $\begin{array}{l}\text { (1) Smithsonian/NASA Astrophysics Data } \\
\text { System }\end{array}$ & http://adsabs.harvard.edu/ \\
\hline 8 & NASA Technical Reports Server & https://ntrs.nasa.gov/search.jsp \\
\hline 9 & $\begin{array}{l}\text { Agecon Search Research in Agricultural and } \\
\text { Applied Economics }\end{array}$ & http://ageconsearch.umn.edu/ \\
\hline 10 & HAL Sciences de l'Homme et de la Société & http://halshs.archives-ouvertes.fr/ \\
\hline
\end{tabular}

\section{E-Journal}

Informasi yang mutakhir dan terpercaya dapat diperoleh dari berbagai sumber dan salah satunya dari jurnal (Tercetak ataupun elektronik). E-Journal sebagai forum untuk pertukaran antara ide, inovasi, hasil penelitian, praktik terbaik, perkembangan di media cetak dan bahan sumber daya non-cetak. Apabila E-Journal dimanfaatkan secara maksimal tentu mendorong untuk mengetahui isu-isu terbaru, melahirkan inovasi atau agent of change, memacu kegiatan penelitian dan mengerak terjadinya lifelong learning (Suadi and Makmur 2015, 72).

Ironisnya E-Journal belum dimanfaatkan secara maksimal. Karana didasari atas ketidaktahuan alamat E-Journal, tidak mengetahui cara menelusuri informasi di E-Journal atau bisa jadi tidak memahami katagori spesifik subjek E-Journal sebab setiap journal memiliki spefisikasi subjek yang berbeda dan tidak sembarang orang yang bisa mengaksenya terutama jurnal berupatasi nasional atau internasional harus memiliki username dan password (Suadi and Makmur 2015, 74).

Namun perlu diperhatikan oleh masyarakat informasi tatkala memanfaat e-journal yang bersifa Open Access (jurnal gratis) memperhatikan beberapa faktor agar informasi diperoleh memiliki unsur kebenaran dan ilmiah antara lain: (1) Apakah mereka anggota DOAJ? Directory Open Access Jurnal, (2) Periksa apakah jurnal memiliki faktor dampak (impact factor). Seberapa tinggi dampak faktornya?, (3) periksa pedoman peer review jurnal apakah diposting secara terbuka, (4) identifikasi dewan redaksinya, (5) apakah jurnal terindeks di database utama atau jasa indeks, (6) Cari sejarah public jurnal? Apakah jurnal memiliki jadwa publikasi regular? Berapa banyak masalah atau jurnal diterbitkan per tahun, (7) siapa saja penulis yang pernah menerbtikan di jurnal tersebut? Periksa siapa saja mengirim artikel kesana dan apakah semua dari instansi yang sama? Apakah kelompok atau 
satu penulis yang dominan?, (8) Bagaimana kualitas artikel di jurnal? Berapa banyak yang membaca artikel, apakah ditulis dengan baik atau menyedia metode ilmiah yang baik, (9) apakah penelitian berafiliasi dengan Universitas terkemuka. Apakah lembaga memiliki program atau keahlian di lapangan yang sedang ditulis?, (10) Apakah artikel ini dikutip oleh orang lain atau di bidang yang sama? Untuk memeriksa jumlah kutipan untuk artikel yaitu melalui Web of Science dan Scopus merupakan dua database yang menawarkan kutipan jumlah artikel. Selain itu Google Scholar sekarang mencatat kutipan dan menghitung di tingkat artikel.

\section{E-book}

Revolusi informasi bukanlah hal sulit mencari litelatur maupun informasi dari seluruh penjuru dunia dengan berbagai bahasa, dengan berbagai format. Kini tersedia beberapa website yang menjadi media untuk upload, read, download e-book. Berdasarkan laporan dari Libreka sejauh ini mencatat 25.000 judul E-Book tersebar di internet, bisa dimanfatakan secara gratis, didownload dan merupakan hal penting dalam upaya mengkaya informasi serta pengetahuan. Sudah seharusnya para pencari informasi harus tanggap terhadap kehadiran buku elektronik dan beberapa situs terbaik yang menawarkan ebook yaitu Bookfi.org (Book Finder), Libgen.info (Library Genesis), Gutenberg. Org, Google Books dan sebagainya.

\section{Databases Video sharing}

Dengan adanya situs video sharing memberi keniscayaan dan sangat diminati oleh masyarakat informasi dalam memenuhi kebutuhan informasi dengan format suara, video atau multimedia. Video sharing merupakan website dimana user dapat mengupload video ke website melakukan pemrosesan video dan mengkonverisnya ke format flash video (.flv) kemudian pengunjung dapat melihat video tersebut dengan gratis.

Informasi dari video sharing seperti video klip, trailer film, video personal, game trailer, tutorial dan iklan. Situs video sharing akan mempermudah mencari video berkualitas, media untuk berkreasi dan mencari inspirasi. Situs video sharing terpopuler: (1) Youtube, (2) Internet Movie Database, (3) FFlick.

\section{STRATEGI PENELUSURAN INFORMASI}

Untuk memastikan ketersedian informasi dan memudahkan dalam penelusuran informasi maka masyarakat informasi harus memiliki keahlian, khususnya dalam strategi penelusuran informasi di internet, baik keahlian menelusuri yang bersifat sederhan hingga yang advance. Perlunya strategi penelusuran informasi agar tidak terjebak dengan jutaan informasi, tersasar di halaman Search Engine, tidak menghabiskan waktu lama, kebinggungan memilih, menyaring atau menilai informasi yang overload, akhirnya tidak memperoleh informasi yang sesuai dan berdampak pada tingkat kepuasan (Suadi and Makmur 2015, 28). Apalagi ketergantungan masyarakat informasi pada search engine tidak dipungkiri lagi. Misalnya melihat data dari http://www.searchenginecollossus.com dapat disimpulkan bahwa kepedulian atau kebutuhan masyarakat informasi terhadap mesin pencari yaitu (1) lebih dari $80 \%$ pengguna internet menemukan situs yang dicari melalui mesin pencari, dan /(2) lebih dari 1 Milyar pengguna Internet melakukan pencarian informasi melalui mesin pencari setiap harinya. Data yang sama juga disampaikan dengah hasil survey CSIS (Center Strategic And International Studies) menyatakan penetrasi millineal terhadap sumber informasi dan salah satu media sering digunakan ialah media online yang digunakan setiap hari.(CSIS 2017) 
Namun seringkali tidak diimbangi atau dibekali dengan keahlian penelusuran informasi. Ditambah pula dari keterangan Indrajit(n.d.) bahwa kebanyakan dari pencari informasi yang telah terbiasa berinteraksi di dunia maya rata-rata baru mempergunakan 5$10 \%$ dari "kekuatan" internet yang sebenarnya. Hal ini disebabkan banyaknya para pengguna internet belum mengetahui teknik "searching" yang tepat dan efektif sehingga berkolerasi terhadap perolehan data, informasi, relevansi pengetahuan yang dibutuhkannya terutama dalam usaha untuk mengembangkan diri dan mempermudah pekerjaan atau aktivitas sehari-hari. Padahal untuk saat ini, sudah bukan zamannya lagi tidak memahami atau mengetahui cara mengakses informasi dari berbagai sumber informasi.

Bahkan Hary dan Dewdney sebagaimana dikutip oleh Hervisya (2007, 30) menyatakan bahwa hambatan masyarakat informasi dalam mencari informasi dalam memenuhi kebutuhan informasi dipengaruhi oleh (1) Tidak mengetahui kebutuhan informasi, (2) Tidak mengetahui dimana mendapat informasi yang dibutuhkan, (3) Tidak mengetahui keberadaan sumber informasi yang dibutuhkan, dan (4) Tidak menemukan sumber informasi yang sesuai dengan kebutuhan. Selaras dengan itu terdapat 6 kemampuan penelusuran informasi untuk memberi solusi penelusuran informasi yakni penentuan atau subyek yang dicari, strategi pencarian, lokasi aksesnya, penggunaan informasi, memadukan informasi dan evaluasi (Chowdhary and Chowdhary 2001, 35). Bilamana mempunyai kemampuan strategi penelusuran informasi akan mempermudah pencarian informasi, memperoleh informasi yang relevan bahkan akurat, mampu menghematkan waktu atau biaya, dan mempengaruhi informasi lain yang berkaitan. Untuk mencegah masalah tersebut sudah seharusnya masyarakat informasi harus melek dengan metoe penelusuran informasi atau strategi mencari informasi agar bisa menentukan batasan informasi yang dibutuhkan, bisa memformulasikan kebutuhan informasi, mampu mengidentifikasi sumber-sumber informasi yang tersedia.

Strategi penulusaran informasi yang bisa dipergunakan masyarkat informasi seperti

1. Boolean Query Formulation

Ketika menelusuri informasi sebaiknya atau seharusnya membuat perumusan pertanyaan dan atau permintaan dengan menggunakan operator Boolen AND, OR, NEAR dan NOT

2. Limiting Searches

Limiting Searches dikenal sebagai penelusuran berdasarkan ruas (field searching) dan contohnya sebagai berikut:

Tabel 3. Penelusuran Limiting Searches

\begin{tabular}{|l|l|l|}
\hline \multicolumn{1}{|c|}{ Nama } & \multicolumn{1}{|c|}{ Langkah } & \multicolumn{1}{c|}{ Contoh Penelusuran } \\
\hline $\begin{array}{l}\text { Pencarian melalui ruas } \\
\text { (field searching) }\end{array}$ & $\begin{array}{l}\text { Judul } \\
\text { Search) }\end{array}$ & $\begin{array}{l}\text { (Perpustakaan Era Keterbukaan } \\
\text { Informasi public Search) } \\
\text { (Buyada kerja pustakawan era digital: } \\
\text { perspektif organisasi, relasi dan individu } \\
\text { search) }\end{array}$ \\
\hline $\begin{array}{l}\text { Pencarian melalui ruas } \\
\text { (field searching) }\end{array}$ & $\begin{array}{l}\text { Pengarang (Author } \\
\text { Search) }\end{array}$ & $\begin{array}{l}\text { (Testiani Makmur Search) } \\
\text { (Lasa HS Search) } \\
\text { (Sulistyo-Basuki Search) }\end{array}$ \\
\hline $\begin{array}{l}\text { Pencarian melalui ruas } \\
\text { (field searching }\end{array}$ & $\begin{array}{l}\text { Judul Jurnal } \\
\text { (periodical Tittle } \\
\text { Search) }\end{array}$ & (Visi pustaka search) \\
\hline
\end{tabular}

3. Truncation

Cara penelusuran dikombinasikan atau dipadupadankan dalam menemukan semua bentuk kata yang berbeda, melainkan mempunyai basic kata yang sama. Biasanya 
menggunakan simbol truncation(\#, ?, atau \$) kemudian suatu kata istilah dipenggal atau dipotong pada posisi tertentu, misalnya di kiri, di kanan atau pada keduanya (tengah). Contohnya:

Tabel 4. Penelusuran Truncation

\begin{tabular}{|c|l|l|l|l|}
\hline No & \multicolumn{1}{|c|}{$\begin{array}{c}\text { Posisi } \\
\text { Pemenggalan }\end{array}$} & \multicolumn{1}{c|}{$\begin{array}{c}\text { Cara } \\
\text { Pemenggalan }\end{array}$} & \multicolumn{1}{c|}{ Maksudnya } & Hasil ditemukan \\
\hline 1 & $\begin{array}{l}\text { Posisi (left } \\
\text { truncation); }\end{array}$ & INTERN\# & $\begin{array}{l}\text { Menemukan kata atau } \\
\text { istilah yang dimulai } \\
\text { dengan INTERN }\end{array}$ & $\begin{array}{l}\text { INTERNETINTERNATIO } \\
\text { NALINTERNALINTERM } \\
\text { EZO dsb }\end{array}$ \\
\hline 2 & $\begin{array}{l}\text { posisi kiri (right } \\
\text { truncation); }\end{array}$ & $\# M E N T$ & $\begin{array}{l}\text { Menemukan kata atau } \\
\text { istilah yang berakhiran } \\
\text { MENT }\end{array}$ & $\begin{array}{l}\text { GOVERMENT, } \\
\text { DEVELOPMENT, dsb. }\end{array}$ \\
\hline 3 & $\begin{array}{l}\text { posisi kanan dan } \\
\text { kiri (right and left } \\
\text { truncation) }\end{array}$ & \#TERN\# & $\begin{array}{l}\text { Menemukan kata atau } \\
\text { istilah yang berisikan } \\
\text { sisipan kata TERN }\end{array}$ & $\begin{array}{l}\text { Internship, } \\
\text { Letsinterndan sebagainya. }\end{array}$ \\
\hline
\end{tabular}

4. Menggunakan formulasi alternative (Suadi and Makmur 2015, 34) yang terdiri dari define (untuk mencari defenisi), link (menampilkan daftar link yang mengarahkan kesebuah situs), site (menampilkan pencarian khusus disitus yang ditunjuk), cache (menampilkan situs web yang telah di indeks oleh google meskipun sudah tidak aktif lagi), info (menampilkan informasi tentang sebuah situs), filetype (menampilkan pencarian dengan jenis dokumen tertentu, misalnya mencari pdf, doc, ppt atau sebagainya), INTITTLE (menampilkan kata yang dicari dalam tittle halaman), dan ALLINTITLE ( menapilkan seluruh kata yang dicarai dalam TITTLE halaman).

Tetapi yang perlu diingatkan kembali, sebelum atau ketika menelusuri informasi sebaiknya harus menggunakan Prinsip 6W \& $1 \mathrm{H}$ (What, When, Where, Why, Which, Who dan How). Hasil diperoleh bilamana menerapkan prinsip tersebut yaitu memudah pengakses dalam memformulasi pertanyaan informasi dan strategi mencari informasi di internet.

\section{E. PENUTUP}

Revolusi sumber informasi ialah setiap orang mampu melahirkan, mengakses, memanfaat dan berbagi informasi maupun pengetahun, namun adanya peluang dan tantangan yang akan dihadapi masyarakat informasi atas kebanjiran informasi. Kondisi seperti ini tentunya memberi konsekuensi sendiri bagi masyarakat informasi dan apalagi dengan overloadnya informasi menyebabkan masyarakat informasi kerap mendepati kerumitan untuk memperoleh informasi yang dibutuhkan.

Dibutuhkan keahlian yang mampu menghindari dampak tersebut yaitu (1) Literasi informasi kemampuan analitikal dan kritis atas informasi yang diperoleh dan manfaatnya menjadi pembelajaran sepanjang hayat, kritis dan mampu melebarkan kerangka berpikir tatkala berinteraksi dengan beragam-ragam informasi, (2) Sumber-sumber informasi memberi kebebasan, kemudahan masyarakat informasi dalam menulusuri sumber-sumber informasi dan dan sumber informasi internet antara lain Online Public Access Catalog, repository, e-journal, eboook dan data video sharing. (3) Strategi penelusuran informasi merupakan satu keharus yang harus dimiliki masyarakat informasi, agar bisa menentukan batasan informasi yang dibutuhkan, bisa memformulasikan kebutuhan informasi, mampu mengidentifikasi sumber-sumber informasi yang tersedia. Strategi penulusaran informasi 
yang bisa dipergunakan masyarkat informasi Boolean Query Formulation, Limiting Searches, Truncation, menggunakan formulasi alternative dan menggunakan prinsip $6 \mathrm{~W}+1 \mathrm{H}$.

\section{DAFTAR PUSTAKA}

Ahmad, Amar. 2012. "Perkembangan Teknologi Komunikasi Dan Informasi: Akar Revolusi Dan Berbagai Standarnya." Jurnal Dakwah Tabligh 13 (1): 139.

Ainiyah, Nur. 2017. "Membangun Penguatan Budaya Literasi Media Dan Informasi Dalam Dunia Pendidikan.” Jurnal Pendidikan Islam Indonesia 2 (1): 65-77. https://doi.org/10.35316/jpii.v2i1.63.

Ardoni. 2005. "Teknologi Informasi: Kesiapan Pustakawan Memanfaatkannya." Pustaha: Jurnal Studi Perpustakaan Dan Informasi 1 (2): 1.

Badke, William. n.d. "Foundations of Information Literacy: Learning from Paul Zurkowski." Researchgate.Net. Accessed December 10, 2018. https://www.researchgate.net/publication/293703989_Foundations_of_information _literacy_Learning_from_paul_zurkowski.

Chowdhary, G. G, and S Chowdhary. 2001. Searching CD-Rom and Online Information Sources. London: Library Association Pub.

CSIS. 2017. "Ada Apa Dengan Milenial?Orientasi Sosial, Ekonomi Dan Politik." The Centre for Strategic and International Studies. 2017. https://www.csis.or.id/uploaded_file/event/ada_apa_dengan_milenial__paparan_ survei_nasional_csis_mengenai_orientasi_ekonomi_sosial_dan_politik_generasi_ milenial_indonesia_notulen.pdf.

Darmono. 2007. Perpustakaan Sekolah: Pendekatan Aspek Manajemen Dan Tata Kerja. Jakarta: Grasindo.

Hakim, Heri Abi Burachman. 2015. "Internet Dan Kapitalisme Informasi Di Perpustakaan." Info Persada 13 (2): 2-12.

Hervisya, Novalia. 2007. "Pemanfaatan Koleksi Perpustakaan Dalam Pemenuhan Kebutuhan Informasi Pengguna." Skripsi, Jatinangor: Universitas Padjadjaran.

Indrajit, Richardus Eko. n.d. "Teknik Searching Efektif Di Internet Memanfaatkan Dunia Maya Untuk Menambah Ilmu Pengetahuan Dan Kualitas Personal.” Accessed November 30 , 2018. http://eprints.binadarma.ac.id/1462/1/PRAKTIKUM\%20INTERNET.pdf.

Iskandar. 2016. "Literasi Informasi: Perspektif Pustakawan" 15 (1): 5.

Masiani, Ketut. 2015. "Mempertahankan Keberadaan Perpustakaan Khusus Dalam Globalisasi Informasi." Jurnal Pari 1 (1): 36.

Muntasir. n.d. "Standard Kompetensi Literasi Informasi Dan Pengajarannya Di Perguruan Tinggi."

Nuryaman. n.d. "Defnisi Dan Sejarah Perkembangan IL Di Indonesia Dan Dunia." Academia.Edu. Accessed December 9 , 2018. https://www.academia.edu/11686520/Sejarah_Literasi_Informasi.

O’ Connor, L., and Jill Newby. n.d. "Entering Unfamiliar Territory Building an Information Literacy Course for Graduate Students in Interdisciplinary Areas." Researchgate.Net. Accessed $\quad$ December 2018. https://www.researchgate.net/publication/281606143_Entering_Unfamiliar_Territo ry_Building_an_Information_Literacy_Course_for_Graduate_Students_in_Interdis ciplinary_Areas. 
Rifai, Agus. n.d. "Teknologi Media Informasi Di Perpustakaan.” Accessed December 11, 2018. https://www.scribd.com/document/360460161/PUST2243-M1.

Suadi, Depi, and Testiani Makmur. 2015. Revolusi Sumber Informasi Digital. Yogyakarta: Bulak Sumur Empat.

Sudarsono, Blassius. 2007. Literasi Informasi: Pengantar Untuk Perpustakaan Sekolah. Jakarta: Perpustakaan Nasional RI.

Sukaesih, and Rohman. 2013. "Literasi Informasi Pustakawan: Studi Kasus Di Universitas Padjadjaran.” Jurnal Kajian Informasi Dan Perpustakaan 1 (1): 62.

Surachman, Arif. 2017. "Gadjah Mada Knowledge Hub: Cetak Biru Portal Web Institutional Repository Berbasis Connected-Resources.” In , 8. Banda Aceh.

Toffler, A.G. 1980. Future Shocks The Third Wave. New York: Bantam.

Triningsih, Catharina Esmi. n.d. "Literasi Informasi Pustakawan: Studi Kasus Di Universitas Padjadjaran." Accessed December 10, 2018. http://ejournal.uajy.ac.id/12419/1/PerA6883.pdf.

UNESCO. n.d. "Information Literacy." Communication and Information. Accessed November 17, 2018. http://www.unesco.org/new/en/communication-andinformation/access-to-knowledge/information-literacy/.

Webster, Frank. 1995. Theories of the Information Society. 3rd ed. New York: Routldge. 